심한 발열과 혈압 변동을 보인 양측 시상하부를 포함하는 다발성 양측 뇌경색 1예 류승호 김병석 이정규 이동현

명지병원 신경과

\title{
Multiple Bilateral Infarction Involving Bilateral Hypothalamic Lesion Presented with High Fever, Unstable Blood Pressure
}

\author{
Seung-Ho Ryu, Byoung Seok Kim, Jeong Kyu Lee, Dong Hyun Lee
}

Department of Neurology, Myongji Hospital, Goyang, Korea

Hypothalamic infarction is uncommon because of abundant blood supply from the Willis circle. Here, we report a patient who had a sizable ischemic stroke including bilateral hypothalami and was suffered from extremely-high fever and fluctuating blood pressure.

\section{J Neurosonol Neuroimag 201\$;10(1):41-44}

Key Words: Hypothalamus; Cerebral infarction; Hyperthermia; Hypernatremia
Received: June 4, 2018

Revised: June 16, 2018

Accepted: June 16, 2018

Address for correspondence: Dong Hyun Lee

Department of Neurology, Myongji Hospital, 55 Hwasuro, 14beon-gil, Deogyang-gu, Goyang 10475, Korea Tel: +82-31-810-5418 Fax: +82-31-969-0500 E-mail: bigeasy77@naver.com
시상하부는 뇌간의 원심 구조물이며 체온 조절, 삼투압, 면 역반응 조절, 식이섭취 조절, 생식, 생물학적 리듬, 자극에 대 한 통합된 반응을 포함하여 항상성 조절에 중요한 역할을 한 다. ${ }^{1}$ 시상하부는 기능적으로 뇌실 주위, 내측 그리고 측면 영역 으로 나뉜다. 이처럼 시상하부는 다른 기능을 하는 각각의 핵 으로 나누어져 있지만, 통합된 자율, 내분비, 행동 반응을 위 해서는 서로 상호작용이 필요하다. ${ }^{1}$ 감염, 종양, 사고 등에 의 한 시상하부 이상은 이전에 보고된 사례가 수차례 있으나, 뇌 경색으로 인한 시상하부 이상은 보고된 사례가 드물다. ${ }^{2}$ 저자 들은 양측 시상하부 뇌경색과 관련된 고열 및 급격한 혈압 변 동을 나타낸 사례가 있어서 보고하고자 한다.

\section{증 례}

49세 여자가 당일 오전 계단에서 구른 이후에 발생한 지 남력 저하로 내원하였다. 고혈압, 하지불안증후군이 있었고, 갑상선 수술을 받았었다. 응급실 방문 당시 혈압은 $175 / 75$ $\mathrm{mmHg}$, 분당 심박수 122 회, 체온은 37.8 도였다. 신경학적 검 사상 각성도, 뇌간 반사, 운동 및 감각 신경은 정상이었다. 하 지만 의사 표현을 하지 못하고 간단한 지시에도 협조가 되지
않았으며, 양측에 바빈스키 반사가 있었다. 일반혈액검사에서 혈당 $395 \mathrm{mg} / \mathrm{dL}$, 총 콜레스테롤 $243 \mathrm{mg} / \mathrm{dL}$, 크레아틴 키 나아제 $297 \mathrm{U} / \mathrm{L}$, 백혈구 19,100/uL, 당화혈색소 $15.0 \%$ 의 상 승이 있었다. 확산강조 자기공명영상에서 전두엽에 국한된 국 소 다발성 병변이 있었으나, 시상하부는 정상이었다(Fig. 1A). 컴퓨터뇌혈관단층촬영에서 우측 경동맥 근위부 및 좌측 경동 맥 원위부 폐색이 있었고, 전순환계는 척추기저동맥으로부터 후교통동맥을 통하여 혈류 공급을 받고 있었다(Fig. 1B). 입 원 첫째 날 좌하방으로 안구편위가 있어서 뇌파검사를 하였으 나 중등도 이상의 전반적인 서파만 있었다. 입원 2일째 40 도 이상의 고열과 의식이 저하되어 반혼수 상태가 되었으며 대뇌 제거자세를 취하였다. 고열의 원인을 찾기 위하여 가슴과 복부 컴퓨터단층촬영, 혈액, 객담, 소변에서 세균배양검사 및 뇌척 수액검사를 하였으나 감염의 증거는 없었다. 경흥부 심장 초음 파검사에서 심장내 덩어리는 없었고 심장 기능에 문제가 없었 으나, 수축기 혈압이 큰 폭으로 변동하였다(Fig. 2A). 뇌경색 악화 및 출혈성 변환을 확인하기 위하여 입원 2일째에 촬영한 확산강조 자기공명영상에서 양측 시상하부를 포함하여 양측 전대뇌동맥 영역 및 좌측 중대뇌동맥 영역 전반에 걸쳐 뇌경색 이 있었다(Fig. 1 C). 감염의 증거는 뚜렷하지 않고, 시상하부 손상이 영상검사에서 확인되어서 이로 인한 중추성 고열의 가 
Seung-Ho Ryu, et al. Bilateral Hypothalamic Infarction and Unstable Vital Status
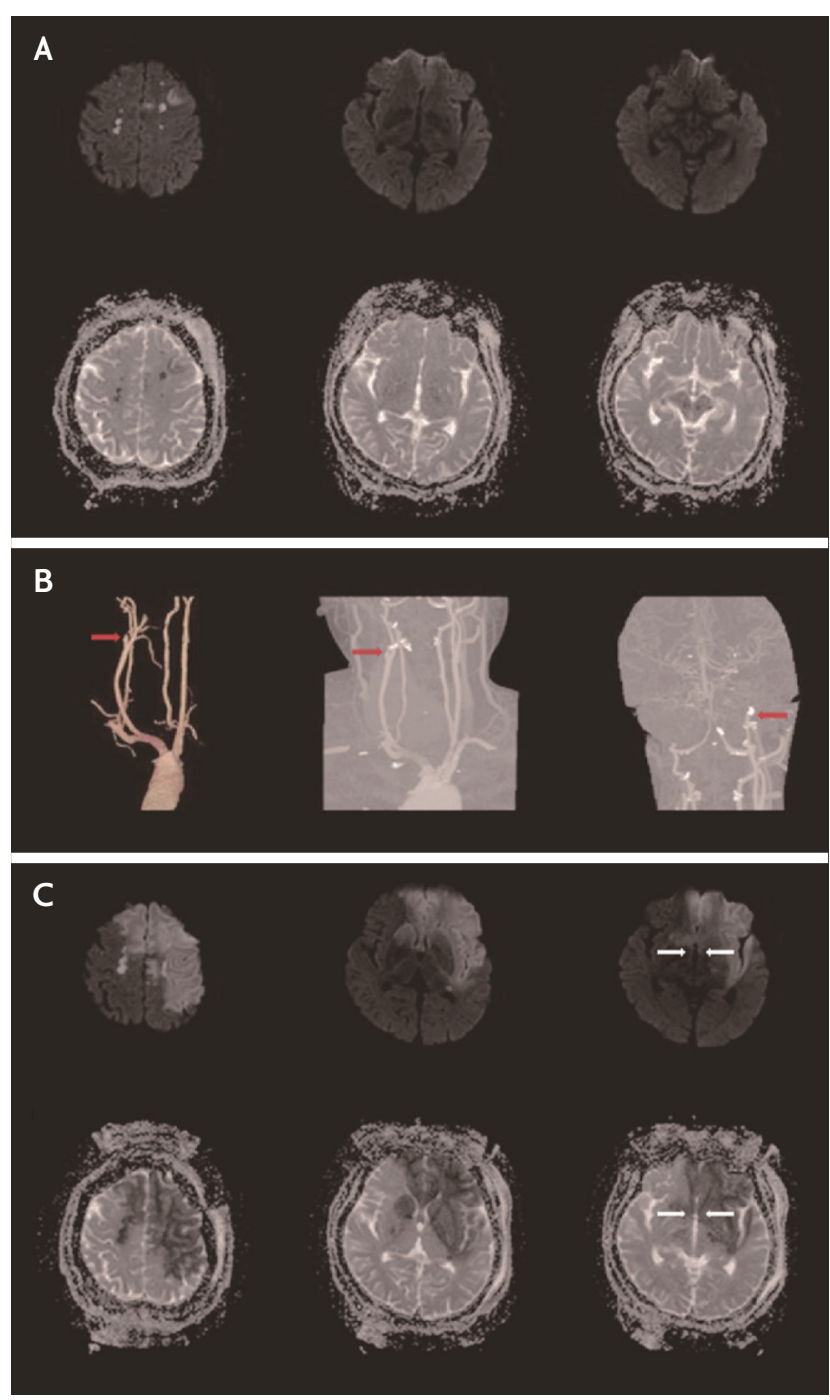

FIG. 1. Diffusion weighted imaging (DWI) and Computed tomography angiography (CTA). (A) Initial DWI showed multiple variable sized acute infarctions in bilateral frontal cortices and white matters. (B) CTA demonstrated complete occlusion (red arrows) of the right proximal internal carotid artery (ICA) and the left distal ICA. (C) Follow-up DWI showed newly developed acute infarctions in the left hemispheres including frontotemporoparietal cortices and white matters and in the bilateral internal capsules and hypothalami (white arrows).

능성이 높았다. 환자는 dantrolene 정맥투여를 시작하여 증량 하면서 체온은 정상 범위로 회복되었다(Fig. $2 B$ ). 대뇌제거자 세도 그 정도가 감소하였다. 입원 4일째부터 호흡부전(ataxic breathing pattern 및 이산화탄소 정체)이 발생하여 기관삽 관 및 기계호흡을 시작하였다. 혈액검사에서 혈중 삼투압 상승 및 고나트륨혈증 $(170 \mathrm{mmol} / \mathrm{L})$ 이 생겼고, 만니톨 등 이뇨제를 사용하지 않았음에도 불구하고 지속적인 수분이 배출되었으며 수축기 혈압이 70-80 mmHg으로 낮아서 수액공급 및 승압제 를 시작하였다. 입원 6 일째부터는 다발성 장기 손상과 이에 따 른 합병증이 생기기 시작하였고 19 일째 사망하였다.

\section{고 찰}

시상하부는 전뇌동맥에서 분지되는 전내동맥, 후뇌동맥의 근위부에서 분지되는 시상줄무늬천공지동맥과 후교통동맥에 서 분지되는 소동맥에서 각각 전시상하부와 후시상하부 혈액 공급을 받는다. ${ }^{3}$ 이처럼 전, 후 뇌동맥에서 풍부한 혈액 공급 을 받기 때문에 시상하부에 뇌경색이 발생하는 경우는 매우 드 물다.

시상하부의 뇌경색으로 호너증후군이 발생한 보고들은 여러 차례 알려져 있지만, ${ }^{4}$ 이외의 시상하부 기능저하를 나타낸 보 고는 흔하지 않다. 물리적 혈관손상에 의하여 선택적으로 양 측 전시상하부 영역에 뇌경색이 발생하여 체온조절이상, 수분 균형 조절장애, 수면조절이상, 부정맥이 생긴 사례 ${ }^{2}$ 와 시상하 부에 유육종성 육아종(sarcoid granuloma)이 있다가 한쪽 시 상하부에 출혈성 뇌경색병소가 생기면서 저체온증을 보인 보 고가 있으나 영상검사 없이 부검에 의한 병리 소견을 바탕으로 기술하였다. ${ }^{5}$ 국내에서도 시신경교차증후군으로 내원하여 전 시상하부뇌경색이 동반된 사례가 있었으나 시상하부 기능저하 에 대한 언급은 없었고, ${ }^{6}$ 다식증과 수면과다로 일측성 배내측 시상하부 뇌경색이 자기공명영상에서 확인된 보고가 있다. ${ }^{7}$ 증 례의 환자는 양측 내경동맥이 폐색되어 후방순환계에서 측부 순환을 통하여 혈류가 불충분하게 공급되던 상태여서 양측 시 상하부에 뇌경색이 발생한 것으로 보인다.

체온 변화는 내측 시각전핵과 전시상하부핵의 온도민감 신 경세포에서 감지하는데, 본 환자에서는 감염에 대한 증거는 없 었으나, 고체온증이 지속되었으며 일반 해열제에 반응이 전혀 없었다. 신경이완제 및 항정신병약 복용에 대한 과거력은 없었 고, 더불어 dantrolene 투여 이후 체온이 하강한 것으로 미루 어, 본 환자는 내측 시각전핵과 전시상하부핵의 손상이 있었을 것으로 추측하였다. 입원 2 일째부터 소변량이 증가되었고 4 일 째부터는 고나트륨혈증이 생겼는데, 신장기능이상이나 외인 성 인자는 뚜렷하지 않아서 중추성 요붕증에 의한 현상으로 생 각하였다. 뇌하수체와 시상하부를 압박할 정도의 뇌경색 부종 은 동반되지 않아서, 항이뇨호르몬의 분비조절과 수분과 나트 륨 항상성 조절에 필수적인 기능을 담당하는 뇌실방핵 손상으 로 인한 증세로 보았다. 시상하부의 뇌실방핵은 스트레스 반응 의 작동인자로서 앞서 언급한 항이뇨호르몬 분비조절 이외에 도 교감신경계 활성화와 부신겉질 자극호르몬 분비 조절에도 관여한다. ${ }^{1}$ 입원 2 일째 악화되면서 보였던 극심한 수축기 혈압 변동도 뇌실방핵 손상에 의한 교감신경계 활성화 이상에서 비 롯된 증세로 보인다. 결국 본 환자는 시상하부의 전시상하부 영역, 그중에서도 내측 시각전핵, 뇌실방핵, 전시상하부핵 부 위에 손상이 온 것으로 추정할 수 있다(Fig. 3).

시상하부는 자기공명영상검사에서 기능적으로 구획된 핵들 을 개별적으로 구별하기는 어려우며, 일부 백질경로와 주위 구 조물들을 확인하여 경계를 구분할 수 있는 정도이다. ${ }^{8-10}$ 따라 
A Systolic blood pressure at $2 \mathrm{nd}$ day $(\mathrm{mmHg})$

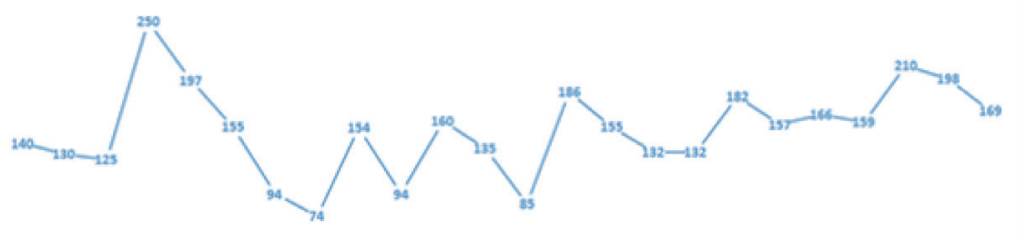

0:00 1:00 2:00 3:00 4:00 5:00 6::00 7:00 8:00 9:00 10:0011:00 12:00 13:00 14:00 15:00 16:00 17:00 18:00 19:00 20:00 21:00 22:00 23:00

B Body temperature at $2 \mathrm{nd}$ day $\left({ }^{\circ} \mathrm{C}\right)$

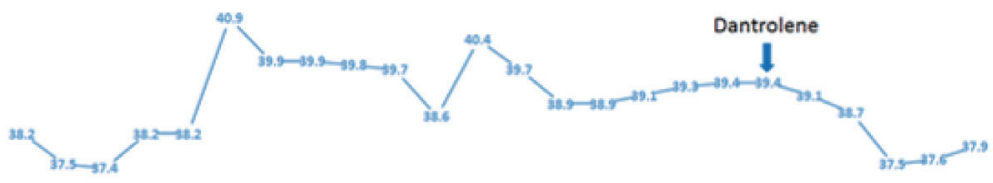

0:00 1:00 2:00 3:00 4:00 5:00 6:00 7:00 8:00 9:00 10:00 11:00 12:00 13:00 14:00 15:00 16:00 17:00 18:00 19:00:20:00 21:00 22:00 23:00

Body temperature at 3 nd $\operatorname{day}\left({ }^{\circ} \mathrm{C}\right)$

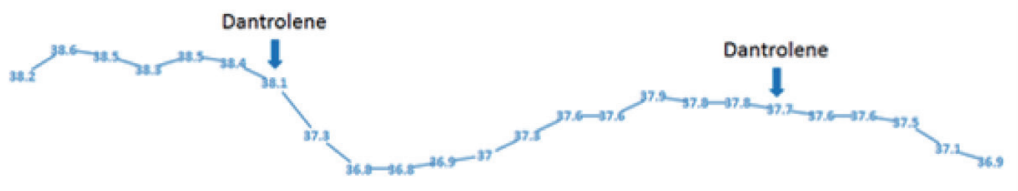

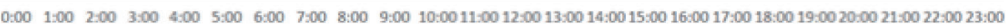

FIG. 2. Monitoring of systolic blood pressure and body temperature of the patient. Serial monitoring of vital signs showed remarkable fluctuation of systolic blood pressure (A) and high spiking fever refractory to antipyretics (B). After intravenous administration of dantrolene, high fever dramatically subsided within 48 hours in the patient.

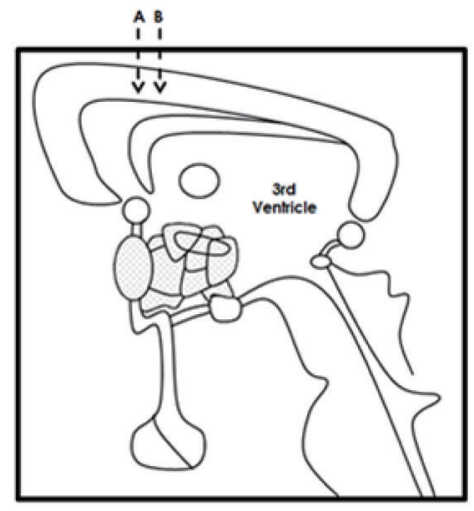

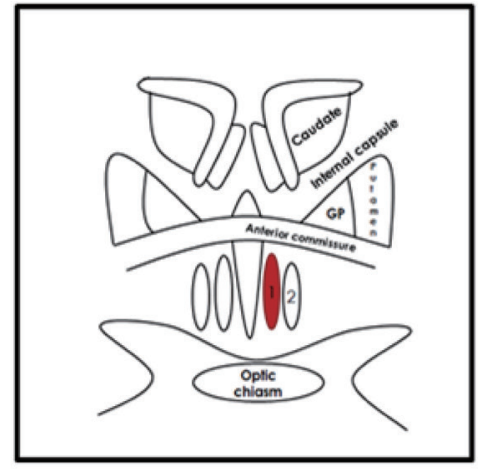

A

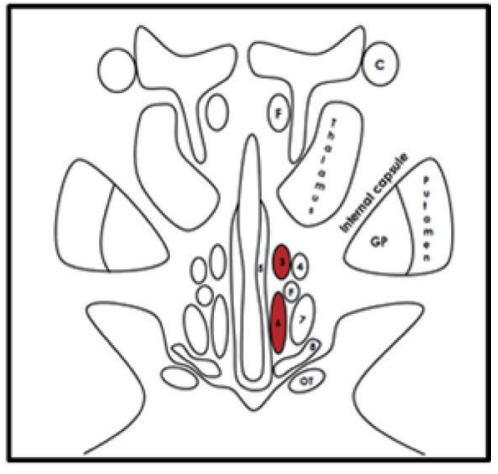

B

FIG. 3. Schematic representation of hypothalamic nuclei and adjacent structures. Left picture showed topographic location of hypothalamic nuclei (stippled area) from sagittal view. Medial (A) and right (B) picture showed normal coronal anatomy of hypothalamic region. We assumed that red-colored hypothalamic nuclei $(1,3,6)$ were responsible for the clinical manifestations of this patient. 1 ; medial preoptic area, 2; lateral preoptic area, 3; paraventricular nucleus, 4; dorsal hypothalamic area, 5; periventricular arcuate nucleus, 6; anterior hypothalamic area, 7; lateral hypothalamic area, 8; supraoptic nucleus, F; fornix, GP; globus pallidus, C; caudate, OT; optic tract. 
서 시상하부 손상에 의한 병소의 영상과 기능저하의 연관성에 대한 연구나 보고가 부족한 현실이다. 본 증례에서도 손상된 것으로 추정되는 시상하부 부위를 자기공명영상에서 개별적으 로 정확히 구분하기는 어려운 한계가 있었다. 하지만 전 시상 하부 영역의 기능저하로 나타나는 다양한 임상양상을 확인할 수 있었고, 원인이 되는 병소를 영상검사로 국재화할 수 있어 서 임상진료현장에서 예시적 가치와 의의가 있다고 생각한다. 특히 본 증례에서 임상적으로 주목할 부분은 광범위한 영역에 발생한 뇌경색에서 심한 혈압변동과 원인불명의 고열이 동반 되었을 경우에는 시상하부의 기능저하로 인한 임상양상은 아 닌지 감별진단에 포함해야 한다는 점이다. 추후 고해상도 자기 공명영상 기법이 더 일반화된다면 시상하부의 기능적 해부와 병소 확인이 용이해 질 것이다.

\section{REFERENCES}

1. Benarroch EE, Cutsforth-Gregory JK, Flemming KD. Mayo clinic medical neurosciences: Organized by neurologic system and level. New York: Oxford University Press, 2017.

2. Rudelli R, Deck JH. Selective traumatic infarction of the human anterior hypothalamus. Clinical anatomical correlation. J Neurosurg. 1979;50:645-654.

3. Daniel PM. The blood supply of the hypothalamus and pi- tuitary gland. Br Med Bull. 1966;22:202-208.

4. Smith CD. A hypothalamic stroke producing recurrent hemihyperhidrosis. Neurology. 2001;56:1394-1396.

5. Branch EF, Burger PC, Brewer DL. Hypothermia in a case of hypothalamic infarction and sarcoidosis. Arch Neurol. 1971;25:245-255.

6. Kim WJ, Kim SM, Sunwoo IN. A case of optic chiasmal and focal hypothalamic infarction. J Korean Neurol Assoc. 1990;8:334-337.

7. Kwon YS, Seo MJ, Yang WS, Yu HJ, Roh SY. A case of unilateral hypothalamic infarction with polyphagia and hypersomnolence. J Korean Neurol Assoc. 2005;23:374-376.

8. Loes DJ, Barloon TJ, Yuh WT, DeLaPaz RL, Sato Y. Mr anatomy and pathology of the hypothalamus. AJR Am J Roentgenol. 1991;156:579-585.

9. Miller MJ, Mark LP, Yetkin FZ, Ho KC, Haughton VM, Estkowski L, et al. Imaging white matter tracts and nuclei of the hypothalamus: an MR-anatomic comparative study. AJNR Am J Neuroradiol. 1994;15:117-121.

10. Saeki N, Sunami K, Kubota M, Murai H, Takanashi J, Iuchi T, et al. Heavily T2-weighted MR imaging of white matter tracts in the hypothalamus: normal and pathologic demonstrations. AJNR Am J Neuroradiol. 2001;22:1468-1475. 